\title{
Tubulointerstitial nephritis and uveitis syndrome; a T-lymphocyte disease
}

\author{
Hurtarte Sandoval AR ${ }^{1}$, Sánchez Sánchez R ${ }^{2}$, Espinosa Hernández M¹, Ortega Salas R $^{2}$ and Aljama García P $^{1}$ \\ ${ }^{1}$ Department of Nephrology, Reina Sofia Hospital, Cordoba, Spain \\ ${ }^{2}$ Department of Pathology, Reina Sofia Hospital, Cordoba, Spain
}

\begin{abstract}
We can find a tubulointerstitial nephritis in up to $3 \%$ of renal biopsies, and about $12-15 \%$ when acute renal failure is present. Tubulointerstitial nephritis and uveitis (TINU syndrome) is a rare condition, with very few cases reported in the literature. Usually presents the combination of renal failure and uveitis, being diagnosed with renal biopsy, and a diagnosis of exclusion. We describe the case of a TINU syndrome diagnosed by renal biopsy findings characteristic of predominant $\mathrm{T}$-lymphocytes and mast cells, with good response to corticosteroid treatment.
\end{abstract}

\section{Introduction}

The first case was described in 1975. The TINU syndrome is a very rare disease; there have been reported more than 250 cases in the literature [1]. TINU syndrome is the combination of tubulointerstitial nephritis and recurrent uveitis. Most cases have been reported in journals of ophthalmology and paediatrics.

\section{Case report}

A 37 -year-old man was referred by his primary care physician for elevated creatinine $(258.13 \mathrm{mmol} / \mathrm{L})$. With a background of uveitis during the last four years, and no specific aetiology, he was treated with prednisone; however, he went 6 months without any medical treatment due to complete remission. There was no history of, hematuria, oliguria or other urinary symptoms. He denied the use of any medications regularly. Ophthalmologic examination revealed left anterior uveitis; the rest of the physical examination was unremarkable. Laboratory examination revealed mild normocytic anemia with $11.9 \%$ eosinophilia, serum creatinine $282.8 \mathrm{mmol} / \mathrm{L}$ (reference 35.4-97.2), a positive IgG antibodies against Epstein Barr virus. Urianalysis revealed proteinuria $1500 \mathrm{mg} / 24$ hours without erythrocyturia. Other tests, including serum complement, IgG, subclasses of IgG, IgM, rheumatoid factor, antinuclear antibodies, anti- double-stranded -DNA antibodies, antibodies anti-SS-A/SS-B antibodies, antineutrophil cytoplasmic antibodies, HLA -B27, angiotensin-converting enzyme (ACE) levels), blood/urine cultures, stool analysis, stool culture, antibodies against treponema pallidum, aspergillus, galactomannan antigen, echinococcus, brucella, toxoplasma gondii, HIV serology, Mantoux test, and hepatitis $\mathrm{B} / \mathrm{C}$, showed negative/normal results. The Chest X-Ray was normal. The Renal ultrasound revealed increased echogenicity and decreased corticomedullary ratio. Renal biopsy was performed by analyzing 22 glomeruli, 11 of them sclerotic, with moderate tubular atrophy, and interstitial fibrosis. The interstitial inflammation was multifocal and mixed type, with no signs of vasculitis and absence of granulomas. The study of immunofluorescence for IgA, IgG, IgM, C3, fibrinogen, C1q and light chains (K/L) were negative. The Immunophenotyping of interstitial inflammatory infiltrate highlighted a higher proportion of $\mathrm{T}$ lymphocytes (CD3) on B lymphocytes (CD20), with a low proportion of plasma and macrophage cells, as well as accumulation of mast cells in areas of greater chronicity (Figure 1). We finally diagnose tubulointerstitial nephritis and uveitis (TINU syndrome); we started treatment with intravenous methylprednisolone $250 \mathrm{mg}$ and topic corticosteroids each day, for three consecutive days and then oral prednisone $1 \mathrm{mg} / \mathrm{Kg} /$ day. Our patient, one month later improved with a serum creatinine of $221 \mathrm{mmol} / \mathrm{L}$. Evidence suggests that modified C- reactive protein (mCRP), an autoantigen present in the renal tubular cells and uvea is associated in its pathogenesis (2). Delayed-type hypersensitivity and suppressed cell-mediated immunity with a predominance of T-lymphocytes and mast cells likely play a significant role as our case demonstrated. Renal tubulointerstitial infiltrates are primarily composed of activated T-lymphocytes $[3,4]$. Has predominance in adolescence and is more common around the 15 years old. There have been identified up to $50 \%$ of cases as triggers the use of NSAIDs, chinese herbs (goreisan), hypoparathyroidism, hyperthyroidism, IgG4 - related disease, concurrent chlamydial infection and Epstein - Barr virus. The main clinical manifestations are fever, weight loss, abdominal pain, arthralgias, myalgias and may be associated with uveitis. Renal manifestations include abdominal pain mainly on flanks, sterile pyuria, polyuria, nocturia, hematuria and proteinuria in subnephrotic range. Laboratory findings can reveal anemia, elevated erythrocyte sedimentation rate, eosinophilia, presence of cytoplasmic antineutrophil antibody (ANCA) [5], rheumatoid factor or hypocomplementemia. TINU syndrome diagnosis is nonspecific and is made by the combination of uveitis and renal involvement, with renal biopsy consistent with acute tubulointerstitial nephritis.

Correspondence to: Dr. Aldo René Hurtarte Sandoval, Servicio de Nefrología, Hospital Universitario Reina Sofía, Avda Menéndez Pidal s/n, Cordoba 14004, Spain, Tel: 34-957-010440; Fax 34-957-010307; E-mail: aldohurtarte12@hotmail.com

Key words: tubulointerstitial nephritis, uveitis, T-lymphocyte disease

Received: December 02, 2015; Accepted: January 04, 2016; Published: January 07,2016 


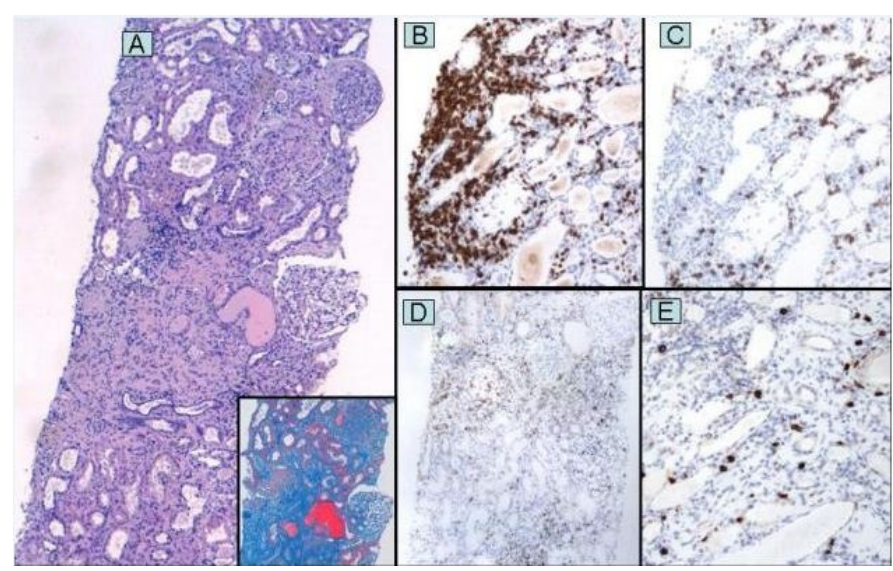

Figure 1. (A) Renal biopsy showing moderate interstitial inflammation, tubular atrophy and interstitial fibrosis (Hematoxylin and eosin, original magnification x 40; insert: Masson trichrome, original magnification $x$ 100). (B) High proportion of $\mathrm{T}$ lymphocytes (CD3 immunostaining, original magnification $\mathrm{x} 100$ ). (C) Less proportion of $\mathrm{B}$ lymphocytes (CD20 immunostaining, original magnification $x$ 100). (D) Low proportion of macrophage cells (CD68 immunostaining, original magnification $x$ 100). (E) Accumulation of mast cells in areas of greater chronicity (CD117 immunostaining, original magnification x 40).

Typical findings include tubulointerstitial edema and inflammatory infiltration, cells composed mostly of mononuclear cells, such as T-lymphocytes, mast cells, plasma cells and histiocytes. Findings with immunofluorescence and electron microscopy are nonspecific. The differential diagnosis includes sarcoidosis, sjögrens's syndrome, systemic lupus erythematosus, Behcet's disease, toxoplasmosis, histoplasmosis, tuberculosis. Prognosis is favorable with full recovery in $80 \%$ of cases and depends on the degree of tubulointerstitial fibrosis. Patients with progressive renal failure are treated with prednisone $1 \mathrm{mg} / \mathrm{kg}$ for three to six months and then slowly tapered. Uveitis has a favorable response due to the use of topical and systemic corticosteroids. Hausler et al. [6] reported recently a case of TINU syndrome refractory to corticoids and cyclosporine that had a favorable outcome after treatment with adalimumab in combination with methotrexate.

\section{Acknowledgements}

This case report was presented as a poster at the Andalusian Congress of Nephrology in April 2014.

The authors also want to thanks to Sheyla Rangel Burgos.

\section{References}

1. Li C, Su T, Chu R, Li X, Yang L (2014) Tubulointerstitial nephritis with uveitis in Chinese adults. Clin J Am Soc Nephrol 9: 21-28. [Crossref]

2. Tanaka H, Suzuki K, Nakahata T, Tateyama T, Waga S, et al. (2001) Repeat renal biopsy in a girl with tubulointerstitial nephritis and uveitis syndrome. Pediatr Nephrol 11: 885-887. [Crossref]

3. Yano N, Miyazaki M, Endoh M, Kuramoto T, Eguchi K, et al. (1991) Idiopathic acute interstitial nephritis associated with uveitis. Jpn J Med 30: 548-552. [Crossref]

4. Tan T, Yu F, Qu Z, Su T, Xing GQ, et al. (2011) Modified C-reactive protein might be a target autoantigen of TINU syndrome. Clin J Am Soc Nephrol 2011; 6: 93. [Crossref]

5. Simon AH, Alves-Filho G, Ribeiro-Alves MA (1996) Acute tubulointerstitial nephritis and uveitis with antineutrophil cytoplasmic antibody. Am J Kidney Dis 28: 124 [Crossref]

6. Häusler U, Guminski B, Helmchen U, et al. (2013) Tubulointerstitial nephritis with uveitis (TINU) syndrome. A relatively rare rheumatological differential diagnosis with unexplained uveitis. Z Rheumatol 72: 393-7. [Crossref]

Copyright: (2016 Hurtarte Sandoval AR. This is an open-access article distributed under the terms of the Creative Commons Attribution License, which permits unrestricted use, distribution, and reproduction in any medium, provided the original author and source are credited. 